\title{
Simultaneous analysis of polychlorinated biphenyls and polychlorinated naphthalenes by isotope dilution comprehensive two- dimensional gas chromatography high-resolution time-of-flight mass spectrometry
}

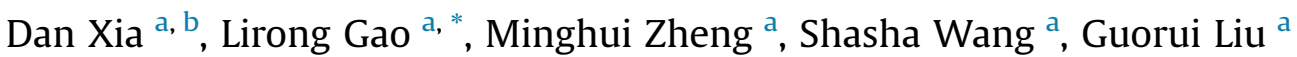 \\ a State Key Laboratory of Environmental Chemistry and Ecotoxicology, Research Center for Eco-Environmental Sciences, Chinese Academy of Sciences, \\ Beijing 100085, China \\ ${ }^{\mathrm{b}}$ University of Chinese Academy of Sciences, Beijing 100085, China
}

\section{H I G H L I G H T S}

- A novel method for simultaneous analysis of 18 PCBs and 16 PCNs was developed using isotope dilution GC $\times$ GC-HRTOF-MS.

- Complete separation of all target analytes was achieved with column combination of DB-XLB $\times$ BPX-70.

- GC $\times$ GC-HRTOF-MS results agreed well with those obtained by GCHRMS.

- Non-target contaminants including OCPs and PAHs were identified in three species of fish.

\section{A R T I C L E I N F O}

\section{Article history:}

Received 29 April 2016

Received in revised form

12 July 2016

Accepted 15 July 2016

Available online 25 July 2016

\section{Keywords}

Polychlorinated biphenyls

Polychlorinated naphthalenes

Comprehensive two-dimensional gas

chromatography

High-resolution time-of-flight mass spectrometry

\section{G R A P H I C A L A B S T R A C T}

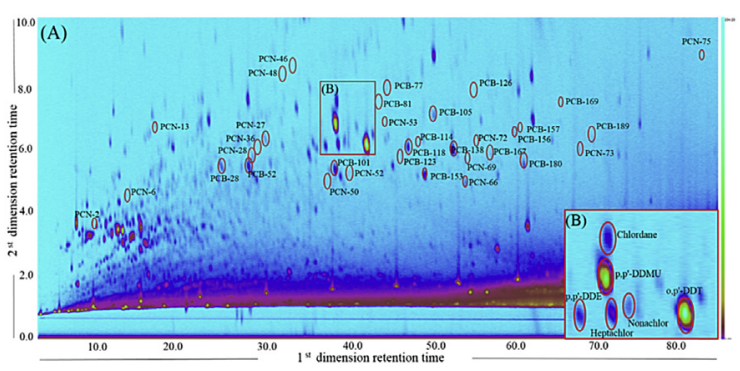

\begin{abstract}
A B S T R A C T
Polychlorinated biphenyls (PCBs) and polychlorinated naphthalenes (PCNs) are listed as persistent organic pollutants (POPs) under the Stockholm Convention. Because they have similar physical and chemical properties, they are coeluted and are usually analyzed separately by different gas chromatography high-resolution mass spectrometry (GC-HRMS) methods. In this study, a novel method was developed for simultaneous analysis of six indicator PCBs, 12 dioxin-like PCBs, and 16 PCNs using isotope dilution comprehensive two-dimensional gas chromatography with high-resolution time-of-flight mass spectrometry (GC $\times$ GC-HRTOF-MS). The method parameters, including the type of GC column, oven temperature program, and modulation period, were systematically optimized. Complete separation of all target analytes and the matrix was achieved with a DB-XLB column in the first dimension and a BPX-70 column in the second dimension. The isotope dilution method was used for quantification of the PCBs and PCNs by GC $\times$ GC-HRTOF-MS. The method showed good linearity from 5 to $500 \mathrm{pg}^{-1} \mathrm{~L}^{-1}$ for all the target compounds. The instrumental limit of detection ranged from 0.03 to $0.3 \mathrm{pg}_{\mu} \mathrm{L}^{-1}$ for the $18 \mathrm{PCB}$ congeners and from 0.09 to $0.6 \mathrm{pg} \mu \mathrm{L}^{-1}$ for the $16 \mathrm{PCN}$ congeners. Repeatability for triplicate injections was always lower than $20 \%$. The method was successfully applied to the determination of 18 PCBs present at $0.9-2054 \mathrm{pg} \mathrm{g}^{-1}$ and 16 PCNs present at $0.2-15.7 \mathrm{pg} \mathrm{g}^{-1}$ in three species of fish. The GC $\times$ GCHRTOF-MS results agreed with those obtained by GC-HRMS. The GC $\times$ GC-HRTOF-MS method proved to be a sensitive and accurate technique for simultaneous analysis of the selected PCBs and PCNs. With the excellent chromatographic separation offered by GC $\times$ GC and accurate mass measurements offered by
\end{abstract}

\footnotetext{
* Corresponding author

E-mail address: gaolr@rcees.ac.cn (L. Gao).
} 
HRTOF-MS, this method allowed identification of non-target contaminants in the fish samples, including organochlorine pesticides and polycyclic aromatic hydrocarbons.

\section{Introduction}

Polychlorinated biphenyls (PCBs) and polychlorinated naphthalenes (PCNs) are synthetic organic compounds with many distinct congeners. Both classes of chemicals are persistent organic pollutants (POPs), which are characterized by high levels of persistence, toxicity and bioaccumulation, and have adverse effects on biota and human health $[1,2]$. Both PCBs and PCNs are listed in the Stockholm Convention on POPs, with PCBs being in the original list of chemicals and PCNs added more recently [3,4]. Historically, PCBs and PCNs were widely used in the electrical industry as dielectric fluids in transformers and capacitors, and as cable insulators [5]. Because of this widespread use, they are ubiquitous in many environmental matrices worldwide [6-9], and are even found in the Antarctic [10].

PCBs and PCNs have similar physicochemical properties, and are usually present in the same fraction during sample preparation processes [11]. Moreover, PCNs have similar chromatographic retention behavior to some coplanar PCBs, which makes it difficult to completely separate these compounds chromatographically. Among the 209 PCBs and 75 PCNs congeners, 12 dioxin-like PCBs and $16 \mathrm{PCNs}$ have attracted the most attention because of their possible dioxin-like toxicity [12]. In addition, six indicator PCBs have been found at high levels in various environmental matrices [12]. Consequently, it is of important to be able to separate these specific PCBs and PCNs from other congeners and contaminants. Although there are some high-resolution capillary columns that can separate some of PCB and PCNs congeners, no chromatographic method can unambiguously and simultaneously separate the 12 dioxin-like PCBs, six indicator PCBs, and 16 PCNs from the other PCBs and PCNs $[13,14]$. Consequently, PCBs and PCNs are usually analyzed separately by gas chromatography coupled with highresolution mass spectrometry (GC-HRMS) in selected ion monitoring mode using ${ }^{13} \mathrm{C}$ isotope dilution for quantification in two injections [11,15]. GC-HRMS instrumentation is expensive, has high operating costs, and requires highly trained personnel to operate it. In addition, multiple injections are needed in GC-HRMS to analyze different classes of compounds. Therefore, alternative methods that can generate results comparable to GC-HRMS are required.

The most promising alternative is comprehensive twodimensional gas chromatography $(\mathrm{GC} \times \mathrm{GC})$, which can produces two-dimensional chromatograms. This method uses a modulator to connect two columns with different polarities, and has the potential to improve separation of the target compounds [16-18]. Narrow peaks (50-200 ms) are obtained from fast separation in the second dimension, and require fast detectors with high scan rates and full scan acquisition [19]. GC $\times$ GC coupled with high-speed low-resolution (LR) time-of-flight (TOF)-MS has been used for the separation and determination of several environmental contaminants in complex samples, and offers high separation power through combination of the chromatographic and mass spectral resolution [20-25]. Hoh et al. developed a GC $\times$ GC high-speed LRTOF-MS method for analyzing polychlorinated dibenzodioxins and furans (PCDD/Fs) at an acquisition rate of $50 \mathrm{~Hz}$ [26]. This separated the $\mathrm{PCDD} / \mathrm{Fs}$ from $\mathrm{PCBs}$, and gave a detection limit for tetrachlorodibenzo- $p$-dioxin of $0.25 \mathrm{pg}$. However, GC $\times$ GC-LRTOFMS is not successful with trace amounts of compounds $\left(\mathrm{pg} \mathrm{L}^{-1}\right)$ in highly complex matrices with low mass resolution. Shunji et al. reported a GC $\times$ GC high-resolution TOF-MS $(\mathrm{GC} \times \mathrm{GC}-\mathrm{HRTOF}-\mathrm{MS})$ method for PCDDs and PCDFs with a resolving power of 5000, acquisition range of $m / z 35-500$, and acquisition rate of $25 \mathrm{~Hz}$ [27]. The high mass resolution and mass accuracy of HRTOF-MS allowed for discrimination of any interferences from the target compounds in environmental samples. However, GC $\times$ GC-HRTOF-MS with a low data acquisition rate $(25 \mathrm{~Hz})$ may increase errors in the quantification. GC $\times$ GC-HRTOF-MS with a faster data acquisition rate $(>100 \mathrm{~Hz})$ could maximize compound separation, eliminate matrix interferences, and greatly improve the selectivity [28]. To the best of our knowledge, simultaneous analysis of different classes of compounds in various matrices using high speed GC $\times$ GC-HRTOFMS has not been reported.

The objectives of this study were to develop a GC $\times$ GC-HRTOFMS method for simultaneous determination of PCBs and PCNs, including the 12 dioxin-like PCBs, six indicator PCBs, and 16 PCNs congeners, in one injection. The GC $\times$ GC and HRTOF-MS parameters were optimized to obtain separation of the targeted congeners and exclude possible interferences. The GC $\times$ GC-HRTOF-MS results were compared with those obtained by GC-HRMS. Meanwhile, the identification and screening of non-target contaminants in the fish samples were conducted using GC $\times$ GC-HRTOF-MS

\section{Materials and methods}

\subsection{Chemicals and standards}

US Environmental Protection Agency (EPA) Method 1668C standard solutions, including PCB 1668C-PAR, labeled calibration and cleanup solution (1668C-LCS), injection standard spiking solution (1668C-IS), and PCN-MXA and PCN-MXC (containing 16 PCN congeners), were used for spiking and calibration and were obtained from Wellington Laboratories (Guelph, Canada). ECN-5102 and ECN-5260 were purchased from Cambridge Isotope Laboratories (CIL; Tewksbury, MA). All solvents were pesticide residue analysis grade. Five solutions of unlabeled (native) compounds were prepared for construction of a calibration curve with concentrations between $5 \mathrm{pg} \mu \mathrm{L}^{-1}$ and $500 \mathrm{pg} \mu \mathrm{L}^{-1}$. Solutions of ${ }^{13} \mathrm{C}$ labeled internal standards were prepared at $100 \mathrm{pg} \mu \mathrm{L}^{-1}$.

\subsection{Sample preparation}

Three different types of fish (yellow croaker, thornback and flatfish) were all lean fish and collected from Bohai Bay, China in July 2013, wrapped in aluminum foil, and stored at $-20{ }^{\circ} \mathrm{C}$ until analysis. Each fish sample (fish muscle with skin not attached) was homogenized and freeze-dried. Fish samples were prepared and analyzed by GC $\times$ GC-HRTOF-MS and GC-HRMS. The results are all presented in picograms of the target compound per gram of fish fresh weight (fw). The sample extraction and cleanup procedures followed US EPA Method 1668 and have been described in detail previously $[11,28,29]$. Briefly, a $10 \mathrm{~g}$ (dry weight) fish sample was spiked with $1 \mathrm{ng}$ of ${ }^{13} \mathrm{C}_{12}$-labeled PCB internal standards (1668CLCS) and ${ }^{13} \mathrm{C}_{10}$-labeled PCN internal standards (ECN-5102). The sample was then extracted with a 1:1 mixture of dichloromethane and $n$-hexane using an ASE 350 extraction unit (Dionex, CA, USA) at 
an extraction temperature of $120{ }^{\circ} \mathrm{C}$ and a pressure of $10.35 \mathrm{MPa}$. The thermal equilibration time was $10 \mathrm{~min}$, and static extractions were performed using three 10 min cycles. Then, the cell was purged with nitrogen for 120 s. The extract was then passed through silica gel treated with $44 \%$ (mass fraction) sulfuric acid, a multilayer silica gel column, and a basic alumina column. The cleaned extract was evaporated to about $10 \mu \mathrm{L}$ under reduced pressure and then under a gentle stream of nitrogen. Injection standards of ${ }^{13} \mathrm{C}_{12}$-labeled PCB (1668C-IS) and ${ }^{13} \mathrm{C}_{10}-1,2,3,4,5,7-$ hexachloronaphthalene (PCN-64) (ECN-5260; CIL) were then added as internal standards for calculation of recoveries.

\subsection{GC $\times$ GC-HRTOF-MS}

The GC $\times$ GC-HRTOF-MS analysis was performed using an Agilent 7890A GC instrument (Agilent Technologies, Santa Clara, CA, USA) fitted with a ZX2004 loop cryogenic modulator (Zoex Corporation, Houston, TX, USA) interfaced with a HRTOF-MS instrument (Tofwerk, Thun, Switzerland), which was operated in electron ionization mode with an ionization energy of $70 \mathrm{eV}$. The data acquisition speed was $100 \mathrm{~Hz}$. Total ion monitoring was performed in full scan mode in the range $m / z 50-500$. The instrument was tuned to a resolving power of 5000 , calculated using the full width at half maximum, using perfluoroperhydrophenanthrene for calibration of the masses. The exact masses of the main perfluoroperhydrophenanthrene ions produced by electron ionization $(\mathrm{m} / z$ 261.9845, 280.9829, 311.9814, 361.9782, 404.9766, 423.9750, $461.9718,585.9654,604.9638$, and 623.9622 ) were used to perform a pulse mass calibration after analysis of each sample. The firstdimension column was a DB-XLB column $(20 \mathrm{~m} \times 0.25 \mathrm{~mm}$ i.d., $0.25 \mu \mathrm{m}$ film thickness, $100 \%$ dimethyl polysiloxane; Agilent Technologies). The second-dimension column was a BPX-70 column ( $2 \mathrm{~m} \times 0.1 \mathrm{~mm}$ i.d., $0.1 \mu \mathrm{m}$ film thickness, 70\% cyanopropyl polysilphenylene siloxane; SGE, Melbourne, Australia). The carrier gas was helium at a constant flow rate of $1.0 \mathrm{~mL} / \mathrm{min}$. Each sample $(1 \mu \mathrm{L})$ was injected in splitless mode with an injection port temperature of $280{ }^{\circ} \mathrm{C}$. The oven program started at $100{ }^{\circ} \mathrm{C}$ (held for $1 \mathrm{~min}$ ), then increased at $10^{\circ} \mathrm{C} / \mathrm{min}$ to $180^{\circ} \mathrm{C}$, and then increased at $1.5^{\circ} \mathrm{C} / \mathrm{min}$ to $280^{\circ} \mathrm{C}$ (held for $10 \mathrm{~min}$ ). The hot pulse duration was $300 \mathrm{~ms}$. The modulation period was $10 \mathrm{~s}$. The MS transfer line temperature was $280{ }^{\circ} \mathrm{C}$, and the ion source temperature was $230{ }^{\circ} \mathrm{C}$. The GC $\times$ GC data were obtained, viewed, and processed using GC Image ${ }^{\circledR}$ R2.5 Software (GC Image, Lincoln, NE, USA). This software allowed automated baseline correction and peak area and volume determination for the compounds, with support for highresolution data.

\subsection{GC-HRMS}

The PCBs and PCNs in the extract were also analyzed separately by GC-HRMS (6890N-Waters Micromass Auto-Spec Ultima, Waters Corp., Milford, MA, USA). The HRMS was operated at a resolution of around 10000 in selected ion monitoring mode using the $\mathrm{M}^{+}$or $(\mathrm{M}+2)^{+}$ions or the most abundant ions in the molecular ion cluster. PCB measurements were carried out using a DB-5MS capillary column $(60 \mathrm{~m} \times 0.25 \mathrm{~mm}$ i.d., $0.10 \mu \mathrm{m}$ film thickness; Agilent Technologies). The oven was heated from 80 to $150{ }^{\circ} \mathrm{C}$ at a rate of $15^{\circ} \mathrm{C} / \mathrm{min}$ (held for $3 \mathrm{~min}$ ), then to $270^{\circ} \mathrm{C}$ (held for $3 \mathrm{~min}$ ) at a rate of $2.5^{\circ} \mathrm{C} / \mathrm{min}$, and then to $330^{\circ} \mathrm{C}$ (held for $13 \mathrm{~min}$ ) at a rate of $15^{\circ} \mathrm{C}$ min. PCNs were separated on a DB-5MS capillary column (30 $\mathrm{m} \times 0.25 \mathrm{~mm}$ i.d., $0.25 \mu \mathrm{m}$ film thickness; Agilent Technologies). The oven was heated from 80 (held for $2 \mathrm{~min}$ ) to $180^{\circ} \mathrm{C}$ at a rate of $20^{\circ} \mathrm{C} / \mathrm{min}$, then to $280^{\circ} \mathrm{C}$ (held for $2 \mathrm{~min}$ ) at a rate of $2.5^{\circ} \mathrm{C} /$ $\mathrm{min}$, and then to $330^{\circ} \mathrm{C}$ (held for $5 \mathrm{~min}$ ) at a rate of $10^{\circ} \mathrm{C} / \mathrm{min}$.

\section{Results and discussion}

\subsection{Optimization of the separation on the GC $\times$ GC system}

The GC $\times$ GC method was optimized to enable separation of the 12 dioxin-like PCBs, six indicator PCBs, and 16 PCNs in a single injection. Several different column combinations (DM-5 and BPX-50, DM-5 and BPX-70, and DB-XLB and BPX-70) were tested to maximize chromatographic separation of the selected compounds using GC $\times$ GC coupled to micro electron capture detection $(\mu \mathrm{ECD})$. Based on the results, a DB-XLB column with low polarity and high specificity for PCB separation was selected as the first column for its boiling-point-based selectivity. To obtain high column efficiency, the selected column was $20 \mathrm{~m}$ long with an inner diameter of $0.25 \mathrm{~mm}$. To optimize the separation of the target compounds from co-extracted matrix components, a 2 m-long BPX-70 column with high polarity was selected as the second column. Four sets of congeners, including PCN 27, PCN 28, PCN 36, and PCB 104 (Fig. 1B), PCB 118, PCB 123 and PCB 188 (Fig. 1C), PCB 167 and PCB 202 (Fig. 1D), and PCN 73 and PCB 208 (Fig. 1E), coeluted on the first column. These coeluted compounds were successfully separated by the second column (Fig. 1A), and no coelution of PCBs and PCNs occurred with the GC $\times$ GC method. Particularly worth mentioning was the complete separation of PCN 28 and PCNs 36, which have not been successfully separated before by one-dimensional GC using a DB-5 column [30]. Also, PCNs 27 and PCN 36 were closely eluted by GC $\times$ GC-qMS using Rt- $\beta$ DEXcst and DB-WAX [31], separation of the two PCNs was achieved for the first time in this study. The two-dimensional chromatogram for the target PCBs and PCNs (Fig. 1A) showed good separation of the selected congeners was achieved using the selected column combination.

Many interferences appeared in the matrix bands in the GC $\times$ GC chromatogram, and these may interfere with the quantification. Therefore, the column combination was also optimized for separation of PCBs and PCNs from matrix components. The DB-XLB and BPX-70 column combination gave good separation of the PCBs and PCNs from the matrix in environmental samples. PCBs and PCNs congeners retained longer time than other compounds in the second dimension column, including PCBs 77, 81, 126, and 159, and PCNs 46, 48, and 75, were retained longer on the BPX-70 column because of its selectivity for these compounds.

Other GC $\times$ GC parameters, including the oven temperature program, modulation period, modulator temperature offset, carrier gas flow rate, and ion source temperature were also systematically optimized for separation of the target POPs. The optimum temperature program is detailed in Section 2.3. The running time of PCBs and PCNs were 75.7 and $59 \mathrm{~min}$ in two separate injection using GC-HRMS, as shown in Section 2.4. The overall run time was 85 min in the optimized GC $\times$ GC method, which was acceptable considering that it provided good separation of all the analytes and the matrix in a single run. A modulation period of $10 \mathrm{~s}$ and a modulator temperature offset of $35^{\circ} \mathrm{C}$ preserved the separation achieved in the first column and did not result in wrap-around. The column head pressure was optimized to obtain a stable and optimal linear velocity in the first and second columns. A programmable pressure control inlet was used. After optimization, all the target compounds were well separated and distributed over the GC $\times$ GC chromatographic space. For the HRTOF-MS parameters, a narrow mass window of 0.02 Da was selected to obtain better separation, with which would also increase the selectivity and accuracy. 




Fig. 1. GC $\times$ GC-HRTOF-MS total ion chromatogram (TIC) of $1668 \mathrm{C}$ native standard solutions (including 27 PCBs) and 16 PCNs using DB-XLB and BPX-70 columns.

\subsection{Method development for isotope dilution $G C \times G C$ quantification}

\subsubsection{Calibration curves, linear ranges, and detection limits}

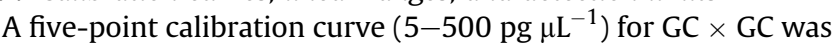
constructed using a standard mixture containing PCBs and PCNs (34 ${ }^{12} \mathrm{C}$-native compounds, shown in Table S1). The compound retention times in the first and second columns and mass spectra were used for qualification (Table 1). The ratios of the two most intense exact mass ions were calculated and compared with theoretical values (tolerance of $20 \%$ ) for identification. The isotope dilution method with ${ }^{13} \mathrm{C}$-labeled internal standard $\left(100 \mathrm{pg} \mu \mathrm{L}^{-1}\right.$ for each) was used for quantification of the PCBs and PCNs. For compounds with no available ${ }^{13} \mathrm{C}$-labeled internal standard, a ${ }^{13} \mathrm{C}$ labeled standard for a compound with a similar structure was used for quantification (Table S1). The set of ${ }^{12} \mathrm{C}$-native and ${ }^{13} \mathrm{C}$-labeled masses for each compound were monitored to identify and quantify the compounds (Table 1). Similar to EPA Method 1668 C for the determination of PCBs [11], isotope dilution GC $\times$ GC quantification was performed by measuring each compound's response for the extracted ${ }^{12} \mathrm{C}$-native mass and ${ }^{13} \mathrm{C}$-labeled mass, then the ratio of the native to ${ }^{13} \mathrm{C}$-labeled response was calculated. A calibration curve was constructed using these response ratios and the ratios of concentrations for native and labeled compounds. Manual combination and corrections of some compound peaks (called "blobs" in GC $\times$ GC) were required for compounds present at low concentrations. Good correlation coefficients $\left(\mathrm{R}^{2}=0.992\right.$ to 0.999$)$ were obtained for the majority of the compounds (Table 1 ). Repeatability was calculated using the relative standard deviation (RSD \%) for triplicate injections of a $50 \mathrm{pg} \mu \mathrm{L}^{-1}$ native standard solution. The RSDs for the PCBs and PCNs were $0.7-15 \%$ and $0.9-17 \%$, respectively (Table 1). The instrumental limits of detection, calculated with a signal-to-noise ratio of three, were between 0.03 and $0.3 \mathrm{pg} \mu \mathrm{L}^{-1}$ for the indicator and dioxin-like PCBs, and 0.09 and $0.6 \mathrm{pg} \mu \mathrm{L}^{-1}$ for the target PCNs. These values were similar to those specified by EPA1668C for GC-HRMS [11]. The method detection limits were calculated by analyzing five replicates of a fish extract (yellow croaker, lean fish) spiked at the lowest level in the calibration curve ( $5 \mathrm{pg} \mu \mathrm{L}^{-1}$ ). The method detection limits varied from 0.6 to $3.5 \mathrm{pg} \mathrm{g}^{-1}$ for PCBs, $0.8-4.6 \mathrm{pg} \mathrm{g}^{-1}$ for PCNs. To assess the method recoveries, three different fish samples were spiked with $1 \mathrm{ng}{ }^{13} \mathrm{C}_{12}$-labeled PCBs (1668C-LCS) and ${ }^{13} \mathrm{C}_{10}$-labeled PCNs internal standard solutions (ECN-5102), extracted, and analyzed by GC $\times$ GC-HRTOF-MS. The recoveries were determined using the labeled injection standards. The mean recoveries ranged from $53 \%$ to $114 \%$ for PCBs, and $47 \%-121 \%$ for PCNs, respectively. The results of the recoveries could meet the criteria of PCBs determination in EPA1668C [11].

\subsubsection{Accuracy evaluation by reference materials analysis}

The accuracy of the method was assessed by analyzing a certified reference material (WMF-01 fish tissue, Wellington Laboratories). The certified reference material was processed according to the extraction and clean-up protocols described in Section 2.2, and then analyzed by the isotope dilution GC $\times$ GC-HRTOFMS method. The analytical results of all dioxin-like PCBs were comparable to the certified values (Table S2). These results demonstrate that the developed GC $\times$ GC-HRTOFMS method produces accurate results.

\subsection{Comparison of GC $\times$ GC-HRTOF-MS and GC-HRMS for analysis of PCBs and PCNs in fish samples}

Samples of three different species of fish (yellow croaker, thornback and flatfish) were analyzed by both GC $\times$ GC-HRTOF-MS and GC-HRMS for the 12 dioxin-like PCBs, six indicator PCBs and 16 PCNs. The data obtained by the two methods were compared. For the two methods, the fish samples were prepared using the same extraction and clean-up procedures, and all samples were prepared in triplicate. Because fish extracts were usually very complex, there were many different compound classes, including PCBs, PCNs, and matrix components, observed in the GC $\times$ GC chromatogram (Fig. 2A).

The GC $\times$ GC-HRTOF-MS results were comparable to those obtained by GC-HRMS (Table 2). The GC $\times$ GC-HRTOF-MS results ranged of $0.9-517.7 \mathrm{pg} \mathrm{g}^{-1}$ for the 12 dioxin-like PCBs, $14.0-2054 \mathrm{pg} \mathrm{g}^{-1}$ for the six indicator PCBs, and $0.2-15.7 \mathrm{pg} \mathrm{g}^{-1}$ for the 16 PCNs. For the six indicator PCBs, the difference between the results from the two methods ranged from 4.7 to $23.9 \%$, indicating that the GC $\times$ GC-HRTOF-MS results were similar to the GC-HRMS results for the three fish species. For the 12 dioxin-like PCBs, those 
Table 1

Masses for quantification of the six indicator PCBs, 12 dioxin-like PCBs, and 16 PCNs, and analytical performance for the optimized GC $\times$ GC-HRTOFMS method.

\begin{tabular}{|c|c|c|c|c|c|}
\hline \multirow[t]{2}{*}{ Compounds } & \multirow[t]{2}{*}{${ }^{1} \mathrm{t}_{\mathrm{R}}(\min ),{ }^{2} \mathrm{t}_{\mathrm{R}}(\mathrm{s})$} & \multicolumn{2}{|c|}{ Quantification masses } & \multirow[t]{2}{*}{ Linearity $\left(r^{2}\right)$} & \multirow[t]{2}{*}{ Repeatability $(\mathrm{RSD} \% \mathrm{n}=5)$} \\
\hline & & Native mass & ${ }^{13} \mathrm{C}$-labeled mass & & \\
\hline PCB-28 & $35.03,5.50$ & 257.9584 & 269.9936 & 0.999 & 5.71 \\
\hline PCB-52 & $36.08,5.78$ & 291.9194 & 303.9597 & 0.999 & 9.02 \\
\hline PCB-101 & $45.22,5.56$ & 325.8804 & 337.9207 & 0.999 & 4.87 \\
\hline PCB-138 & $54.67,6.35$ & 359.8415 & 371.8817 & 0.998 & 7.5 \\
\hline PCB-153 & $55.48,5.98$ & 359.8415 & 371.8817 & 0.998 & 7.5 \\
\hline PCB-180 & $65.89,6.04$ & 393.9025 & 405.8428 & 0.996 & 11.67 \\
\hline PCB-77 & $51.03,8.48$ & 291.9194 & 303.9597 & 0.999 & 9.64 \\
\hline PCB-81 & $49.71,7.72$ & 291.9194 & 303.9597 & 0.999 & 11.14 \\
\hline РCB-105 & $56.02,7.50$ & 325.8804 & 337.9207 & 0.995 & 8.13 \\
\hline PCB-114 & $54.36,6.50$ & 325.8804 & 337.9207 & 0.999 & 4.98 \\
\hline PCB-118 & $53.36,6.38$ & 325.8804 & 337.9207 & 0.999 & 4.47 \\
\hline PCB-123 & $56.02,7.50$ & 325.8804 & 337.9207 & 0.998 & 4.51 \\
\hline PCB-126 & $60.50,8.06$ & 325.8804 & 337.9207 & 0.999 & 9.49 \\
\hline PCB-156 & $64.49,6.83$ & 359.8415 & 371.8817 & 0.998 & 10.79 \\
\hline PCB-157 & $64.82,7.04$ & 359.8415 & 371.8817 & 0.998 & 16.24 \\
\hline РСB-167 & $62.00,6.19$ & 359.8415 & 371.8817 & 0.999 & 8.57 \\
\hline РCB-169 & $62.00,6.19$ & 359.8415 & 371.8817 & 0.998 & 9.69 \\
\hline PCB-189 & $72.96,6.63$ & 393.9025 & 405.8428 & 0.998 & 9.03 \\
\hline $\mathrm{PCN}-2$ & $14.33,3.94$ & 162.0236 & 277.9344 & 0.992 & 6.54 \\
\hline PCN-6 & $19.31,4.97$ & 195.9852 & 277.9344 & 0.997 & 10.79 \\
\hline PCN-13 & $28.61,7.02$ & 229.9469 & 277.9344 & 0.996 & 4.56 \\
\hline PCN-27 & $29.44,7.18$ & 265.9038 & 277.9344 & 0.999 & 7.3 \\
\hline PCN-28 & $37.08,6.09$ & 265.9038 & 277.9344 & 0.986 & 9.38 \\
\hline PCN-36 & $37.41,6.31$ & 265.9038 & 277.9344 & 0.983 & 11.35 \\
\hline PCN-46 & $40.90,8.38$ & 265.9038 & 277.9344 & 0.987 & 7.46 \\
\hline PCN-48 & $42.56,8.59$ & 265.9038 & 277.9344 & 0.991 & 8.32 \\
\hline PCN-50 & $45.22,5.06$ & 299.8648 & 311.8954 & 0.998 & 7.6 \\
\hline PCN-52 & $47.38,5.86$ & 299.8648 & 311.8954 & 0.999 & 9.2 \\
\hline PCN-53 & $50.54,6.93$ & 299.8648 & 311.8954 & 0.998 & 11.82 \\
\hline PCN-66 & $57.68,5.45$ & 333.8258 & 345.8564 & 0.996 & 7.43 \\
\hline PCN-69 & $59.84,6.08$ & 333.8258 & 345.8564 & 0.996 & 13.04 \\
\hline PCN-72 & $60.67,6.35$ & 333.8258 & 345.8564 & 0.994 & 8.66 \\
\hline PCN-73 & $71.47,6.14$ & 367.7869 & 379.8175 & 0.999 & 7.01 \\
\hline PCN-75 & $83.59,8.51$ & 401.7479 & 413.7785 & 0.998 & 6.01 \\
\hline
\end{tabular}

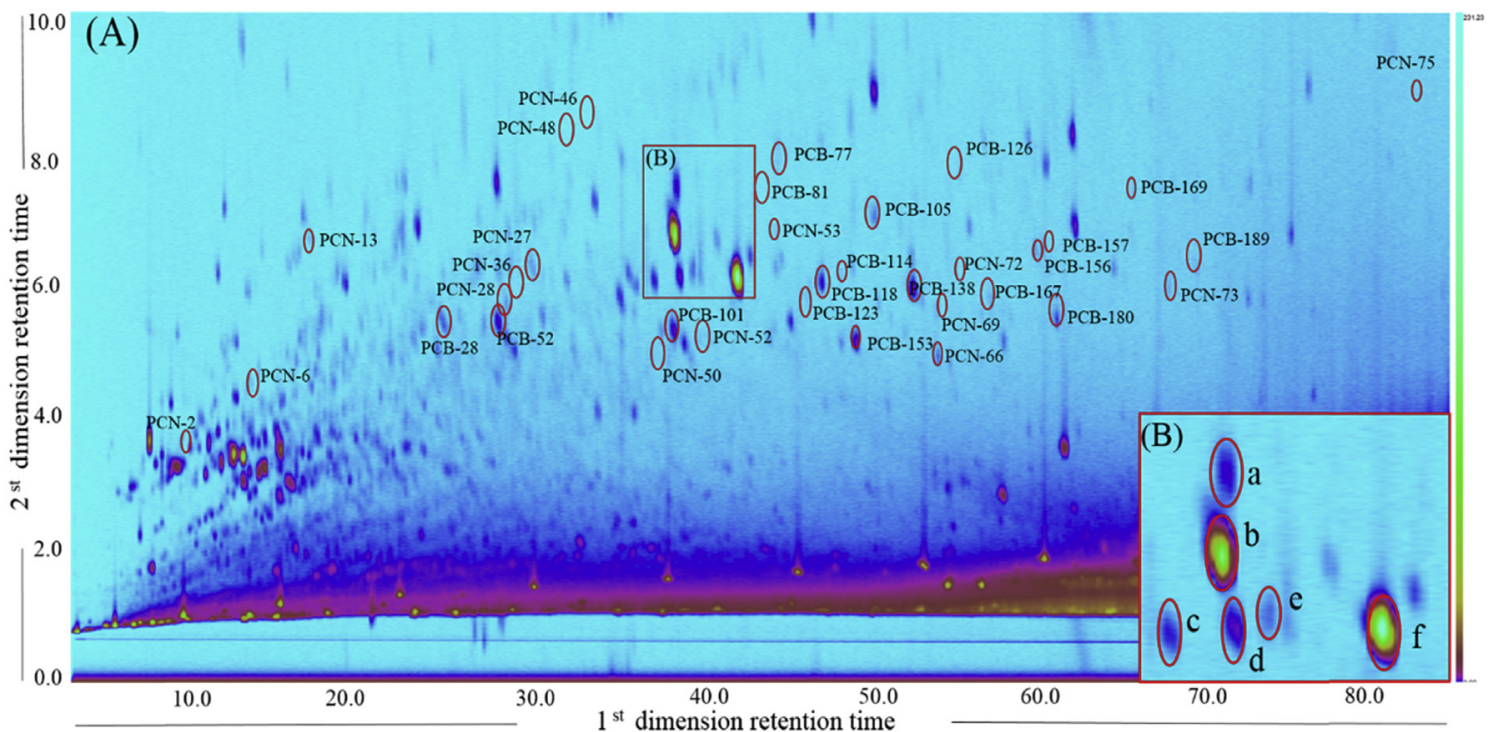

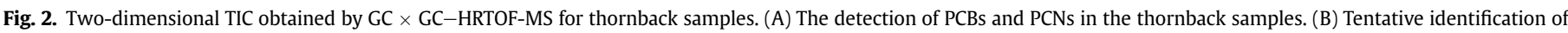
organochlorine pesticides compounds (OCPs) in the thornback samples. (a: Chlordane; b: $p, p^{\prime}$-DDMU; c: $0, p^{\prime}$-DDT; d: Heptachlor; e: Nonachlor and f: $p, p^{\prime}$-DDE).

congeners that were present at concentrations higher than $0.9 \mathrm{pg} \mathrm{g}^{-1}$ gave very similar results with the two methods. The difference between the GC $\times$ GC-HRTOF-MS and GC-HRMS results were below $39.3 \%$ for most congeners (Table 2). For the 16 PCNs, the results from the two methods were in good agreement with each other for most of the analytes. PCNs congeners with concentrations higher than $0.2 \mathrm{pg} \mathrm{g}^{-1}$ gave similar values with the two methods.

Overall, the values obtained by GC $\times$ GC-HRTOF-MS agreed with those obtained by GC-HRMS for PCB and PCNs present at both low and high concentrations. Therefore, GC $\times$ GC-HRTOF-MS is a 
Table 2

Quantitative GC $\times$ GC-HRTOF-MS and GC-HRMS results for 18 PCBs and 16 PCNs in three species of fish.

\begin{tabular}{|c|c|c|c|c|c|c|c|c|c|}
\hline \multirow[t]{2}{*}{ Compound } & \multicolumn{3}{|l|}{ Fish 1 (yellow croaker) } & \multicolumn{2}{|l|}{ Fish 2 (thornback) } & \multicolumn{3}{|c|}{ Fish 3 (flatfish) } & \multirow[b]{2}{*}{$\begin{array}{l}\text { Diff } \\
(\%)\end{array}$} \\
\hline & $\begin{array}{l}\text { GC } \times \text { GC-HRTOF-MS } \\
\left(\mathrm{pg} \mathrm{g}^{-1}\right)\end{array}$ & $\begin{array}{l}\text { GC-HRMS } \\
\left(\mathrm{pg} \mathrm{g}^{-1}\right)\end{array}$ & $\begin{array}{l}\text { Diff } \\
(\%)\end{array}$ & $\begin{array}{l}\mathrm{GC} \times \mathrm{GC}-\text { HRTOF-MS } \\
\left(\mathrm{pg} \mathrm{g}^{-1}\right)\end{array}$ & $\begin{array}{l}\text { GC-HRMS } \\
\left(\mathrm{pg} \mathrm{g}^{-1}\right)\end{array}$ & $\begin{array}{l}\text { Diff } \\
(\%)\end{array}$ & $\begin{array}{l}\text { GC } \times \text { GC-HRTOF-MS } \\
\left(\mathrm{pg} \mathrm{g}^{-1}\right)\end{array}$ & $\begin{array}{l}\text { GC-HRMS } \\
\left(\mathrm{pg} \mathrm{g}^{-1}\right)\end{array}$ & \\
\hline PCB-28 & 244.7 & 261.2 & 6.3 & 728.0 & 770.7 & 5.5 & 236.6 & 253.5 & 6.7 \\
\hline PCB-52 & 130.5 & 147.2 & 11.3 & 1110 & 1205 & 7.9 & 601.4 & 654.8 & 8.2 \\
\hline PCB-101 & 222.9 & 245.2 & 9.1 & 1441 & 1505 & 4.3 & 155.0 & 175.9 & 11.9 \\
\hline PCB-138 & 436.9 & 468.2 & 6.7 & 2054 & 1931 & 6.4 & 170.8 & 179.3 & 4.7 \\
\hline PCB-153 & 461.3 & 495.6 & 6.7 & 2231 & 2365 & 5.7 & 242.6 & 261.6 & 7.3 \\
\hline PCB-180 & 126.8 & 139.2 & 8.9 & 14.0 & 11.3 & 23.9 & 50.7 & 61.2 & 17.2 \\
\hline PCB-77 & 17.4 & 18.7 & 7.0 & 20.9 & 22.7 & 7.9 & 6.7 & 8.5 & 21.2 \\
\hline PCB-81 & 3.5 & 3.4 & 2.9 & 4.2 & 4.7 & 10.6 & 1.6 & 1.2 & 33.3 \\
\hline PCB-105 & 68.0 & 65.2 & 4.3 & 241.1 & 226.6 & 6.4 & 28.2 & 26.8 & 5.2 \\
\hline PCB-114 & 7.1 & 6.6 & 7.6 & 18.0 & 16.2 & 11.1 & 2.9 & 2.7 & 7.4 \\
\hline PCB-118 & 140.1 & 149.5 & 6.3 & 517.7 & 583.1 & 11.2 & 49.8 & 63.9 & 22.1 \\
\hline РCB-123 & 25.5 & 30.6 & 16.7 & 70.4 & 72.1 & 2.4 & 14.6 & 12.6 & 15.9 \\
\hline PCB-126 & 0.9 & 1.2 & 25 & 2.9 & 4.2 & 31 & N.D & 1.1 & - \\
\hline РCB-156 & 8.2 & 25.0 & 67.2 & 23.6 & 80.4 & 70.6 & 2.1 & 7.2 & 70.8 \\
\hline РCB-157 & 8.4 & 7.9 & 6.3 & 22.1 & 20.0 & 10.5 & 4.2 & 3.2 & 31.3 \\
\hline РСB-167 & 7.7 & 7.7 & 0 & 29.0 & 27.5 & 5.5 & 4.9 & 4.5 & 8.9 \\
\hline РСB-169 & 4.3 & 6.6 & 34.9 & 1.9 & 1.2 & 58.3 & N.D & 0.70 & - \\
\hline PCB-189 & 3.2 & 5.0 & 36 & 9.3 & 8.9 & 4.5 & 3.9 & 2.8 & 39.3 \\
\hline $\mathrm{PCN}-2$ & N.D & 0.78 & - & 2.9 & 2.2 & 29.5 & N.D & 0.47 & - \\
\hline PCN-6 & 1.8 & 1.37 & 31.4 & 3.0 & 2.7 & 9.9 & 1.2 & 1.65 & 27.3 \\
\hline $\mathrm{PCN}-13$ & 4.6 & 3.84 & 19.8 & 4.3 & 5.5 & 22.2 & 5.9 & 4.13 & 42.9 \\
\hline PCN-27 & 2.0 & 1.75 & 14.3 & 3.9 & 5.2 & 24.7 & 1.7 & 1.2 & 41.7 \\
\hline PCN-28 & 0.5 & 0.39 & 28.2 & 10.7 & 9.0 & 18.4 & 0.4 & 0.33 & 21.2 \\
\hline PCN-36 & 4.9 & 5.75 & 14.8 & 15.2 & 11.0 & 37.9 & 2.0 & 1.7 & 17.6 \\
\hline PCN-46 & N.D & 0.29 & - & 2.8 & 3.3 & 15.9 & N.D & 0.17 & - \\
\hline PCN-48 & N.D & 0.3 & - & 3.6 & 4.1 & 11.1 & N.D & 0.17 & - \\
\hline PCN-50 & N.D & 0.39 & - & 3.9 & 5.9 & 33.4 & N.D & 0.07 & - \\
\hline PCN-52 & 6.2 & 5.60 & 10.7 & 15.7 & 16.8 & 6.4 & 2.6 & 2.31 & 12.6 \\
\hline PCN-53 & N.D & 0.11 & - & 5.0 & 4.3 & 15.5 & N.D & 0.07 & - \\
\hline PCN-66 & 2.3 & 1.9 & 23.7 & 10.4 & 8.8 & 17.8 & N.D & 0.07 & - \\
\hline PCN-69 & N.D & 0.07 & - & 2.2 & 2.3 & 6.0 & N.D & 0.08 & - \\
\hline PCN-72 & N.D & 0.06 & - & 8.1 & 6.9 & 16.7 & N.D & 0.04 & - \\
\hline PCN-73 & 0.6 & 0.46 & 30.4 & 0.3 & 0.32 & 6.3 & N.D & 0.11 & - \\
\hline PCN-75 & 0.2 & 0.22 & 9.1 & N.D & 0.08 & - & 0.2 & 0.22 & 9.1 \\
\hline
\end{tabular}

Note: Diff (\%) was calculated by (the values of GC-HRMS subtract the values of GC $\times$ GC-HRTOF-MS)/the value of GC-HRMS.

suitable method for simultaneous analysis of multiple classes of compounds in a single run with high selectivity. Compared with GC-HRMS, which requires separate injections to analyze different classes of compounds, the ability to perform the analysis with a single injection by GC $\times$ GC-HRTOF-MS reduces the analytical time. Therefore, GC $\times$ GC-HRTOF-MS could be a good alternative to GC-HRMS for PCBs and PCNs analysis in various environmental matrices. It should be noted that both GC $\times$ GC-HRTOF-MS and HRMS require a high level of skill for instrument maintenance. GC $\times$ GC-HRTOF-MS produces larger data files (5-10 Gb) than GC-HRMS (5-10 Mb), and a computer with a large storage capacity is required. Also, compared to the automatic data processing in GC-HRMS, more expertise were required in handling and processing the large amounts of data produced by GC $\times$ GC-HRTOF-MS. Further improvements in quantification processing software will contribute to improving the efficiency of data process.

\subsection{Screening for non-target classes compounds in the three fish species}

In addition to accurate quantification of PCBs and PCNs, GC $\times$ GC-HRTOF-MS can also be applied to screens for many other classes of pollutants. For example, the chromatograms of a thornback sample (Fig. 2B) and a flatfish sample (Fig. 3) contained both the target analytes and numerous additional compounds. Accurate $\mathrm{m} / \mathrm{z}$ values for the detected non-target compounds and NIST library searches were used in combination with molecular formula calculations for tentative identification of these compounds or compound classes (Table 3). Using GC $\times$ GC mass chromatography with a 0.02 Da wide window, two organochlorine pesticides and several classes of polyaromatic hydrocarbons were identified in this way. Notably, two dichlorodiphenyltrichloroethane metabolites (1chloro-[2,2-bis(4-chlorophenyl)ethenyl]benzene ( $p, p^{\prime}$-DDMU) and 1-chloro-4-[2,2-dichloro-1-(4-chlorophenyl)ethenyl]benzene $\left.\left(p, p^{\prime}-\mathrm{DDE}\right)\right)$ were found at high levels in all of the investigated fish species, indicating that these two compounds have high accumulation potential in fish [32]. In addition, a series of organochlorine pesticides compounds (OCPs) were identified in the thornback sample, including chlordane, $p, p^{\prime}$-DDMU, 1-chloro-2-[2,2,2trichloro-1-(4-chlorophenyl)ethyl]benzene (o,p'-DDT), $p, p^{\prime}$-DDE, heptachlor and nonachlor. For $m / z 220.1585$, a group of compounds corresponding to methylphenanthrene were identified of the flatfish in the GC $\times$ GC chromatograms (Fig. 3). Similarly, same procedure was performed to investigate the presence of other groups of PAHs. Methylated and hydroxylated polyaromatic hydrocarbons were also detected in the flatfish sample (Table 3).

\subsection{Comparison between the developed GC $\times$ GC-HRTOF-MS method and established GC $\times$ GC methods for PCBs and PCNs analysis}

This is the first study of simultaneous quantitative analysis of PCBs and PCNs using isotope dilution GC $\times$ GC-HRTOF-MS. Previously, the development of GC $\times$ GC methods for PCBs analysis has been the subject of several studies. Muscalu et al. developed a $\mathrm{GC} \times \mathrm{GC}-\mu \mathrm{ECD}$ method for routine measurements of PCBs, OCPs, 


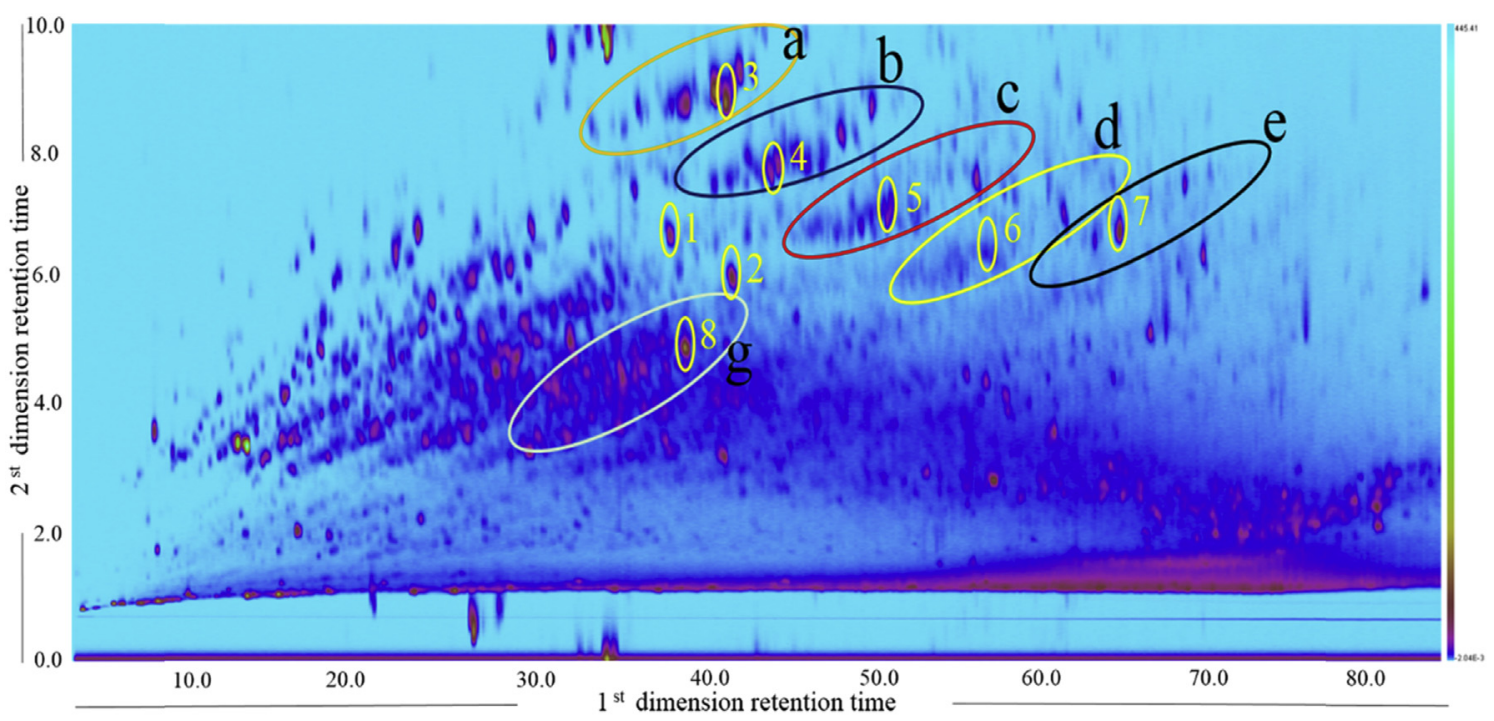

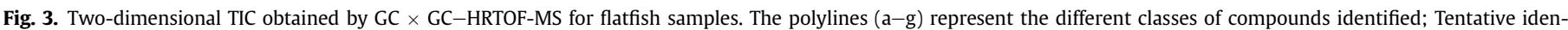
tification of these compounds were shown in Table 3.

Table 3

Identification of other classes of compounds in flatfish sample obtained using GC $\times$ GC-HRTOF-MS.

\begin{tabular}{|c|c|c|c|c|c|c|c|c|}
\hline N.O & Compound & $\mathrm{t}_{\mathrm{R} 1(\min )}$ & $\mathrm{t}_{\mathrm{R} 2(\mathrm{~s})}$ & Formula & Revere & Theoretical $\mathrm{m} / \mathrm{z}$ & Measured $m / z$ & Mass error (mDa) \\
\hline 1 & $\mathrm{p}, \mathrm{p}^{\prime}-\mathrm{DDMU}$ & 43.89 & 6.67 & $\mathrm{C}_{14} \mathrm{H}_{9} \mathrm{Cl}_{3}$ & 895 & 281.9764 & 281.9740 & 24 \\
\hline 2 & $\mathrm{p}, \mathrm{p}^{\prime}-\mathrm{DDE}$ & 47.95 & 6.02 & $\mathrm{C}_{14} \mathrm{H}_{8} \mathrm{Cl}_{4}$ & 893 & 315.9380 & 315.9355 & 25 \\
\hline 3 & 2,3,5-trimethyl-phenanthrene & 46.38 & 8.87 & $\mathrm{C}_{17} \mathrm{H}_{16}$ & 902 & 220.1252 & 220.1285 & 33 \\
\hline 4 & 1,3,6,8-tetramethylanthracene & 49.71 & 7.75 & $\mathrm{C}_{18} \mathrm{H}_{18}$ & 847 & 234.1409 & 234.1447 & 38 \\
\hline 5 & 2-enone,2-methyl-3,4-diphenyl-cyclopent & 55.52 & 6.90 & $\mathrm{C}_{18} \mathrm{H}_{16} \mathrm{O}$ & 776 & 248.1201 & 248.1232 & 31 \\
\hline 6 & 1,2,3,6,7,8,9,10,11,12-decahydrobenzo[e]pyrene & 59.51 & 6.02 & $\mathrm{C}_{20} \mathrm{H}_{22}$ & 774 & 262.1721 & 262.1737 & 16 \\
\hline 7 & 2-methyl-1-(3,4-dimethylbenzoyl)-naphthalene & 71.46 & 7.43 & $\mathrm{C}_{20} \mathrm{H}_{18} \mathrm{O}$ & 757 & 274.1357 & 274.1324 & 33 \\
\hline 8 & 1-(2,3-xylyl)-1-(3,4-xylyl)-ethane & 62.65 & 6.55 & $\mathrm{C}_{18} \mathrm{H}_{22}$ & 820 & 238.1721 & 238.1704 & 17 \\
\hline
\end{tabular}

and chlorobenzenes [33]. Kalachova et al. developed a GC $\times$ GCLRTOF-MS method for analyzing 18 PCBs, seven polybrominated diphenyl ethers, and 16 PAHs [34]. Compared with these studies, the GC $\times$ GC-HRTOF-MS method developed in this study had a lower limit of detection for PCBs (0.03-0.3 pg $\left.\mu \mathrm{L}^{-1}\right)$ and PCNs (0.09-0.6 pg $\mu \mathrm{L}^{-1}$ ) determination. Moreover, the methodology described here enabled quantitative analysis of PCNs for the first time. One benefit of the isotope-dilution GC $\times$ GC-HRTOF-MS method is the use of isotopically labeled internal standards for accurate quantification. Furthermore, with the enhanced chromatographic separation provided by GC $\times$ GC and accurate mass measurements of compounds achieved with the HRTOF-MS 0.02 Da wide window, GC $\times$ GC-HRTOF-MS provided more reliable results than GC $\times$ GC-LRTOF-MS for the identification and screening of non-target contaminants in the fish samples.

\section{Conclusions}

A GC $\times$ GC-HRTOF-MS method for simultaneous quantitative analysis of PCBs and PCNs was developed for the first time. Combination of a DB-XLB column and a BPX-70 column gave excellent separation of the target PCBs and PCNs and the matrix. Thirty-four compounds, including 12 dioxin-like PCBs, six indicator PCBs, and 16 PCNs, in three species of fish were quantified in a single analytical run. The chromatographic separation achieved with GC $\times$ GC was better than that obtained with one-dimensional GC, and its combination with accurate mass measurements by HRTOFMS allowed unambiguous determination of the target compounds in complex matrices. The results obtained in real samples by the developed method were in good agreement with those obtained by GC-HRMS when the PCBs concentrations were higher than $0.9 \mathrm{pg} \mathrm{g}^{-1}$ and PCNs concentrations were higher than $0.2 \mathrm{pg} \mathrm{g}^{-1}$ Moreover, the GC $\times$ GC-HRTOF-MS results could be used for identification of non-target compounds in the fish. The classes of nontarget compounds tentatively identified in this case were organochlorine pesticides and polycyclic aromatic hydrocarbons.

The GC $\times$ GC-HRTOF-MS method is a powerful technique for simultaneous analysis of various classes of compounds, and has enhanced analytical efficiency compared with GC-HRMS. GC $\times$ GCHRTOF-MS could be a feasible alternative for routine analysis of trace environmental pollutants in various environmental matrices.

\section{Acknowledgments}

This research was funded by the National Natural Science Foundation of China (Grant Nos. 21377140, 213111064, 21321004 and 21577152) and the Strategic Priority Research Program of the Chinese Academy of Sciences (XDB14020102). We appreciate the kind support and technical help provided by Dr. Zhanpin Wu (Zoex Corp.), Bin Wang and Xiaolong Jiang (Polytech Instrument Corporation) for operation of the GC $\times$ GC system.

\section{Appendix A. Supplementary data}

Supplementary data related to this article can be found at http:// dx.doi.org/10.1016/j.aca.2016.07.018. 


\section{References}

[1] J.L. Domingo, Polychlorinated naphthalenes in animal aquatic species and human exposure through the diet: a review, J. Chromatogr. A 1054 (2004) $327-334$

[2] K. Kannan, N. Yamashita, T. Imagawa, W. Decoen, J.S. Khim, R.M. Day, C.L. Summer, J.P. Giesy, Polychlorinated naphthalenes and polychlorinated biphenyls in fishes from Michigan waters including the Great Lakes, Environ. Sci. Technol. 34 (2000) 566-572.

[3] D. Lerche, E. van de Plassche, A. Schwegler, F. Balk, Selecting chemical substances for the UN-ECE POP protocol, Chemosphere 47 (2002) 617-630.

[4] UNEP, Stockholm Convention on Persistent Organic Pollutants, 2015. http:// www.pops.int/.

[5] K. Breivik, A. Sweetman, J.M. Pacyna, K.C. Jones, Towards a global historical emission inventory for selected PCB congeners - a mass balance approach-3. An update, Sci. Total. Environ. 377 (2007) 296-307.

[6] A. Martinez, K. Wang, K.C. Hornbuckle, Fate of PCB congeners in an industrial harbor of lake Michigan, Environ. Sci. Technol. 44 (2010) 2803-2808.

[7] T. Harner, M. Shoeib, T. Gouin, P. Blanchard, Polychlorinated naphthalenes in Great lakes air: assessing spatial trends and combustion inputs using PUF disk passive air samplers, Environ. Sci. Technol. 40 (2006) 5333-5339.

[8] G.R. Liu, M.H. Zheng, M.W. Cai, Z.Q. Nie, B. Zhang, W.B. Liu, B. Du, S.J. Dong, J.C. Hu, K. Xiao, Atmospheric emission of polychlorinated biphenyls from multiple industrial thermal processes, Chemosphere 90 (2013) 2453-2460.

[9] G.R. Liu, M.H. Zheng, P. Lv, W.B. Liu, C.Z. Wang, B. Zhang, K. Xiao, Estimation and characterization of polychlorinated naphthalene emission from coking industries, Environ. Sci. Technol. 44 (2010) 8156-8161.

[10] T.F. Bidleman, P.A. Helm, B.M. Braune, G.W. Gabrielsen, Polychlorinated naphthalenes in polar environments - a review, Sci. Total. Environ. 408 (2010) 2919-2935.

[11] US EPA, Method 1668C, Revision C, Chlorinated Biphenyl Congeners in Water, Soil, Sediment, Biosolids, and Tissue by HRGC/HRMS, 2010. EPA-820-R00-005.

[12] Congener-Specific Carbon Isotopic, Analysis of Technical PCB and PCN Mixtures Using Two-dimensional Gas Chromatography-isotope Ratio Mass Spectrometry, 2005.

[13] D. Megson, R. Kalin, P.J. Worsfold, C. Gauchotte Lindsay, D.G. Patterson, M.C. Lohan, S. Comber, T.A. Brown, G.O. Sullivan, Fingerprinting polychlorinated biphenyls in environmental samples using comprehensive twodimensional gas chromatography with time-of-flight mass spectrometry, J. Chromatogr. A 1318 (2013) 276-283.

[14] J. Falandysz, K. Nose, Y. Ishikawa, E. Lukaszewicz, N. Yamashita, Y. Noma, HRGC/HRMS analysis of chloronaphthalenes in several batches of Halowax 1000, 1001, 1013, 1014 and 1099, J. Environ. Sci. Heal. A, Tox/Hazard. Subst. Environ. Eng. 41 (2006) 2237-2255.

[15] P. Korytar, P.E.G. Leonards, J. de Boer, U.A. Th Brinkman, High-resolution separation of polychlorinated biphenyls by comprehensive two-dimensional gas chromatography, J. Chromatogr. A 958 (2002) 203-218.

[16] J. Dalluge, J. Beens, U.A.T. Brinkman, Comprehensive two-dimensional gas chromatography: a powerful and versatile analytical tool, J. Chromatogr. A 1000 (2003) 69-108.

[17] P. Korytar, P.E.G. Leonards, J. de Boer, U.A.T. Brinkman, Group separation of organohalogenated compounds by means of comprehensive two-dimensional gas chromatography, J. Chromatogr. A 1086 (2005) 29-44.

[18] O. Panic, T. Gorecki, Comprehensive two-dimensional gas chromatography $(\mathrm{GC} \times \mathrm{GC})$ in environmental analysis and monitoring, Anal. Bioanal. Chem. 386 (2006) 1013-1023.

[19] M. Harju, C. Danielsson, P. Haglund, Comprehensive two-dimensional gas chromatography of the 209 polychlorinated biphenyls, J. Chromatogr. A 1019 (2003) 111-126.

[20] J.F. Focant, G. Eppe, M.L. Scippo, A.C. Massart, C. Pirard, G. Maghuin-Rogister,
E. De Pauw, Comprehensive two-dimensional gas chromatography with isotope dilution time-of-flight mass spectrometry for the measurement of dioxins and polychlorinated biphenyls in foodstuffs-Comparison with other methods, J. Chromatogr. A 1086 (2005) 45-60.

[21] M. Adahchour, J. Beens, R.J.J. Vreuls, U.A.T. Brinkman, Recent developments in comprehensive two-dimensional gas chromatography $(\mathrm{GC} \times \mathrm{GC})$, Trac. Trends. Anal. Chem. 25 (2006) 438-454.

[22] M. Pena Abaurrea, A. Covaci, L. Ramos, Comprehensive two-dimensional gas chromatography-time-of-flight mass spectrometry for the identification of organobrominated compounds in bluefin tuna, J. Chromatogr. A 1218 (2011) 6995-7002.

[23] Y. Naude, E.R. Rohwer, Two multidimensional chromatographic methods for enantiomeric analysis of o,p '-DDT and o,p '-DDD in contaminated soil and air in a malaria area of South Africa, Anal. Chim. Acta 730 (2012) 120-126.

[24] Y. Zushi, S. Hashimoto, A. Fushimi, Y. Takazawa, K. Tanabe, Y. Shibata, Rapid automatic identification and quantification of compounds in complex matrices using comprehensive two-dimensional gas chromatography coupled to high resolution time-of-flight mass spectrometry with a peak sentinel tool, Anal. Chim. Acta 778 (2013) 54-62.

[25] E. Hoh, K. Mastovska, S.J. Lehotay, Optimization of separation and detection conditions for comprehensive two-dimensional gas chromatography-time-offlight mass spectrometry analysis of polychlorinated dibenzo-p-dioxins and dibenzofurans, J. Chromatogr. A 1145 (2007) 210-221.

[26] H. Shunji, T. Yoshikatsu, F. Akihiro, I. Hiroyasu, T. Kiyoshi, S. Yasuyuki, U. Masaaki, K. Akihiko, T. Kazuo, O. Hideyuki, A. Katsunori, Quantification of polychlorinated dibenzo-p-dioxins and dibenzofurans by direct injection of sample extract into the comprehensive multidimensional gas chromatograph/ high-resolution time-of-flight mass spectrometer, J. Chromatogr. A 1178 (2008) 187-198.

[27] P.Q. Tranchida, F.A. Franchina, P. Dugo, L. Mondello, Comprehensive twodimensional gas chromatography-mass spectrometry: recent evolution and current trends, Mass. Spectrom. Rev. (2014), http://dx.doi.org/10.1002/ mas.21443.

[28] J.C. Hu, M.H. Zheng, W.B. Liu, C. Li, Z.O Nie, G.R. Liu, K. Xiao, S.J. Dong, Occupational exposure to polychlorinated dibenzo-p-dioxins and dibenzofurans, dioxin-like polychlorinated biphenyls, and polychlorinated naphthalenes in workplaces of secondary nonferrous metallurgical facilities in China, Environ. Sci. Technol. 47 (2013) 7773-7779.

[29] Y. Horii, J. Falandysz, N. Hanari, P. Rostkowski, T. Puzyn, M. Okada, K. Amano, T. Naya, S. Taniyasu, N. Yamashita, Concentrations and fluxes of chloronaphthalenes in sediment from Lake Kitaura in Japan in past 15 centuries, J. Environ. Sci. Heal. A, Tox/Hazard. Subst. Environ. Eng. 39 (2004) 587-609.

[30] N. Hanari, J. Falandysz, T. Nakano, G. Petrick, N. Yamashita, Separation of closely eluting chloronaphthalene congeners by two-dimensional gas chromatography/quadrupole mass spectrometry: an advanced tool in the study and risk analysis of dioxin-like chloronaphthalenes, J. Chromatogr. A 1301 (2013) 209-214.

[31] Y. Guo, B.Z. Zhang X.Z Meng H.Y. Yu, Y. Ran, S.M. Li, E.Y. Zeng Occurrence and Fate of 1-Chloro-2,2-bis(4-chlorophenyl)ethane in the Environment of the Pearl River Delta, South China, Environ. Sci. Technol. 43 (2009) 3073-3079.

[32] A.M. Muscalu, E.J. Reiner, S.N. Liss, T. Chen, G. Ladwig, D. Morse, A routine accredited method for the analysis of polychlorinated biphenyls, organochlorine pesticides, chlorobenzenes and screening of other halogenated organics in soil, sediment and sludge by GCxGC- $\mu$ ECD, Anal. Bioanal. Chem. 401 (2011) 2403-2413.

[33] K. Kalachova, J. Pulkrabova, T. Cajka, L. Drabova, J. Hajslova, Implementation of comprehensive two-dimensional gas chromatography-time-of-flight mass spectrometry for the simultaneous determination of halogenated contaminants and polycyclic aromatic hydrocarbons in fish, Anal. Bioanal. Chem. 403 (2012) 2813-2824. 